\title{
Odrodzenie aury z ducha fotogenii
}

\section{Paweł Mościcki}

TEKSTY DRUGIE 2016, NR 2, S. 87-101

DOI: $10.18318 /$ td.2016.2.6

Kino jest takim filtrem rzeczywistości. Zmienia wszystko nawidma.

Karol Irzykowski ${ }^{1}$

Wniektórych przypadkach dzieje się tak, jakby fotografia ujawniała pewna wtaściwość, której oryginat jest pozbawiony: wtaściwość widma. To wtaśnie na tej płaszczyźnie, wyodrębnionej w sposób zdecydowany: widma i obrazu myślowego, należy próbować uchwycić fenomen fotogenii.

Edgar Morin ${ }^{2}$

\section{Paweł Mościcki}

- filozof, eseista i tłumacz, adiunkt w Instytucie Badań Literackich Polskiej Akademii Nauk. Członek redakcji kwartalnika „Widok. Teorie i praktyki kultury wizualnej". Autor książek: Polityka teatru. Eseje o sztuce angażującej (2008), Godard. Pasaże (2010), Idea potencjalności. Możliwość filozofii według Giorgio Agambena (2013), My też mamy już przeszłość. Guy Debord i historia jako pole bitwy (2015).

1 K. Irzykowski Dziesiq̨a muza oraz Pomniejsze pisma filmowe, Wydawnictwo Literackie, Kraków 1982, s. 38.

2 E. Morin Kino i wyobraźnia, przeł. K. Eberhardt, PIW, Warszawa 1975, S. 39 . 
Spectres de Marx, która wprowadziła do dyskursu nauk humanistycznych pojęcie widmontologii. Zgromadzeni na nocnej warcie mężczyźni nie są pewni co właściwie widzieli, co ich spotkało i czy warto wierzyć w realność tego spotkania. W trakcie żywej dyskusji, tym bardziej napiętej, że od pewnego momentu przebiegającej w obecności wspomnianego ducha, który postanowił zjawić się przed nimi ponownie, Marcellus, Bernardo i Horatio czynią kilka mimowolnych spostrzeżeń na temat związków między widmem i obrazem. Dyskurs o widmach wydaje się więc związany nie tylko z problematyką ściśle filozoficzną (widmontologia jako nowa ontologia albo dekonstrukcja ontologii) czy polityczną (wszakże chodzi o widma Marksa i o to, jak nawiedzają myśl i działanie polityczne po zakończeniu zimnej wojny) ${ }^{3}$, ale także z dyskusjami na temat roli i znaczenia obrazów, spotkania między technicznymi mediami i medium zjaw, które nawiedzają, dzięki ich pośrednictwu, nasze spojrzenie.

Po pierwsze, jak zauważa Bernardo, wbrew sceptycznej postawie Horatio, który nie dowierzał opowieściom swych towarzyszy, duch nie jest jedynie fantazją czy urojeniem. Rzecz ta jest „więcej niż złudzeniem [more than fanta-

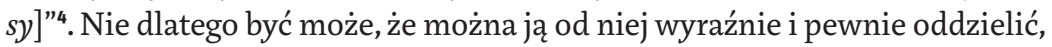
że odzwierciedla jakiś obiektywny stan rzeczy. Widmo jest, przeciwnie, raczej rodzajem zwielokrotnionej lub spotęgowanej fantazji, złudzeniem, które osiąga taki stan skupienia, że staje się niemal realną zjawą. Dlatego też, mimo że trudno w nią uwierzyć, trudno też - to drugie istotne spostrzeżenie, którego autorem jest tym razem sam Horatio - w całości oddalić „jawne i pewne świadectwo mych oczu [the sensible and true avouch of mine own eyes]"5, które nieodparcie wskazuje na jej realność. Jest więc coś takiego w widzeniu, co jest więcej niż udowadnianiem faktów, więcej niż dostrzeganiem tego, co istnieje w zewnętrznej rzeczywistości. I to coś samo w sobie jest realne, tak jak realne jest świadectwo naszego własnego wzroku. Po trzecie, wbrew słownictwu, którym posługuje się Horatio, przywołującemu kontekst sądowniczy (avouch to zeznanie, poręczenie, świadectwo, tak jakby percepcja była permanentnym wydawaniem wyroków na temat świata), wzrok wydaje się tutaj bliżej związany z kwestią etyki, która w dodatku oparta jest na podobieństwie. Marcellus pyta Horatio: „Czy był podobny do króla?”, na co ten odpowiada:

3 Różne wątki i konteksty książki Derridy, por. Ghostly Demarcations. A Symposium on Jacques Derrida's "Specters of Marx", ed. M. Sprinker, Verso Books, London-New York 2008 (1999).

4 W. Shakespeare Hamlet, przeł. M. Słomczyński, Wydawnictwo Zielona Sowa, Kraków 1997, s. 10.

5 Tamże, s. 10. 
"Jak ty do siebie"6. Niby oczywiste - Horatio odpowiada tu innymi słowy, że rozpoznał w pojawiającym się duchu postać króla. Ale zarazem mówi coś więcej, a właściwie mówi coś zgoła innego. Widmo pojawia się dzięki podobieństwu, widmo to zjawa, która domaga się rozpoznania. Zależy ono jednak przede wszystkim od tego, jaką relację z samym sobą ma ten, który na widmo patrzy. To jego podobieństwo do siebie, jego relacja z widmowym wyobrażeniem własnego obrazu, ustanawia miejsce ewentualnego spotkania $\mathrm{z}$ duchem $\mathrm{i}$ jego rozpoznania.

Komentując początkowe sceny z dramatu Shakespeare'a, Derrida zwraca uwagę, że należy „odróżnić widmo nie tylko od ikony czy idola, lecz także od obrazu obrazu, od Platońskiego phantasma, podobnie jak od prostego symulakru czegoś w ogóle, czemu jest ono skądinąd bardzo bliskie i czego niejedną cechę podziela"7. Widmo nie jest więc po prostu obrazem, który zjawia się przed nami i przedstawia jakiś określony wygląd jakiejś określonej rzeczy. To raczej coś w obrazie, co, zjawiając się wraz z nim i dzieląc z nim niejedną własność, jest zarazem czymś odrębnym. Tak jakby widmo nawiedzało tutaj swój własny obraz, czyniąc go niewspółmiernym wobec samego siebie, choć - niczym duch zmarłego króla - niewątpliwie do siebie podobnym. Derrida stwierdza też, że w kontakcie z widmem nie tyle patrzymy na coś, ile „czujemy się widziani przez jakieś spojrzenie, które będzie zawsze niemożliwe do napotkania"8. Na tym osobliwym spotkaniu - byciu obserwowanym bez możliwej wzajemności, wymiany spojrzeń - polega coś, co nazywa on w swej książce „efektem wizjera [l'effet de visière]"

Co jednak obserwuje mnie w nawiedzającym moje oczy widmie, skoro jak zauważyliśmy wcześniej - to moje podobieństwo do mnie samego czyni możliwym jego rozpoznanie? Kto tu na kogo patrzy i z jakiego miejsca? Nie jest więc do końca pewne, z kim się spotykam, gdy spotykam widmo, podobnie jak nie do końca wiem, co we mnie się z nim faktycznie zderza. Czy $\mathrm{w}$ związku z tym samo spotkanie, wydarzenie spotkania, nie traci również swej spoistości, stając się czymś na wskroś widmowym? Czy w ogóle do niego dochodzi, jak przekonują nas świadectwa zmysłów? Nic dziwnego, że Derrida określił widmo jako najlepszy przykład Freudowskiego niesamowitego,

\footnotetext{
6 Tamże, s. 10.

7 J. Derrida Spectres de Marx, Éditions Galilée, Paris 1993, s. 27.

8 Tamże.

9 Tamże.
} 
czegoś w i z nas samych, co nawiedza nas w zaskakującym momencie. Nic też dziwnego, że pełniący nocną straż mężczyźni w Hamlecie po tym dziwnym spotkaniu czuli prawdziwe przerażenie.

\section{Aura, widmo obrazu}

Widmo pojawia się więc wraz z obrazem, nawiedza go, ale zarazem nie daje się do niego zredukować. Jest tym w obrazie, co uczestniczy w jego zjawianiu się, ale zarazem nie jest z nim tożsame. Można więc powiedzieć, że widmo ma cechy podobne do aury, która również stanowi rodzaj dodatku, czy też naddatku, w obrazie, który jednocześnie decyduje o jego wyjątkowości, jego specyficznym i niepowtarzalnym błysku. W gruncie rzeczy okazuje się, że obraz jest najbardziej „sobą” w tym elemencie, który pozostaje wobec niego ekscentryczny; to dzięki niemu faktycznie może się w ogóle pojawić jako obraz. Pojęcie aury to oczywiście jedna z kluczowych kategorii, za pomocą których Walter Benjamin starał się opisywać współczesne nowoczesne przemiany percepcji oraz ich związek z rozwojem mediów technicznej reprodukcji, takich jak fotografia czy film. Więcej jednak, dzięki swym analizom starał się dotrzeć do źródeł współczesnego doświadczenia, które - niczym wspomniane powyżej obrazy - okazują się umykać przed podmiotami, niczym widmo ich własnego losu, którego nie potrafią za nic dogonić.

W pismach Benjamina można odnaleźć dwa zasadnicze sposoby rozumienia aury: jako pewnej dali, dystansu pojawiającego się mimo bliskości i przyswojenia, oraz jako przysługującej rzeczom zdolności odwzajemniania naszego spojrzenia ${ }^{10}$. Najbardziej znana definicja aury pojawia się w Małej historii fotografii z 1931 roku: „Czym właściwie jest aura? Osobliwa pajęczyna z przestrzeni i czasu: niepowtarzalne zjawisko pewnej dali, choćby była najbliżej. [...] Sobie lub raczej masom przybliżyć te rzeczy jest równie namiętnym pragnieniem współczesnych jak namiętna jest chęć przezwyciężenia niepowtarzalności wszelkich zjawisk przez reprodukcję. Z każdym dniem coraz bardziej nieodparcie dochodzi do głosu potrzeba uchwycenia przedmiotu z jak najbliższej odległości w obrazie lub raczej reprodukcji”"1. Już

10 W rekonstrukcji i systematyzacji Benjaminowskich rozważań na temat aury wiele zawdzięczam tekstowi Miriam Bratu Hansen Benjamin's Aura ("Critical Inquiry” Winter 2008 no. 34, s. 336-374). Tam też znaleźć można obszerną bibliografię poświęconą temu zagadnieniu.

11 W. Benjamin Mała historia fotografii (1931), przeł. J. Sikorski, w: tegoż Anioł historii, Wydawnictwo Poznańskie, Poznań 1996, s. 117. 
w tym fragmencie pojawiają się skumulowane wątki przecinające pierwszą definicję aury: splot przestrzeni i czasu, dialektyka bliskości i dali, napięcie między wyjątkowością i reprodukcją.

W Dziele sztuki w dobie reprodukcji technicznej (1936) Benjamin powraca do tych motywów w sposób bardziej systematyczny i wyczerpujący. W tekście tym wydaje się niekiedy przypisywać wartość auratyczną jedynie starym dziełom sztuki, których wyjątkowość zbliżała je do przedmiotów kultu. „Jest więc rzeczą pierwszorzędnej wagi, że dzieło sztuki - z racji aury, stanowiącej nieodłączny atrybut jego istnienia - nigdy nie uwalnia się całkowicie od swej funkcji rytualnej. Inaczej mówiąc: jedyna w swoim rodzaju wartość autentycznego dzieła sztuki ma swoje podłoże w rytuale, w którym posiadało ono swą oryginalną i pierwszą wartość użytkową"12 - pisał. Precyzując jednak znaczenie owej rytualnej, opartej na wyjątkowości dzieła sztuki, funkcji czy genealogii aury, Benjamin wydaje się sprawę komplikować i zarazem przemieszczać.

Definicja aury jako „niepowtarzalnego zjawiska pewnego oddalenia, choćby miało być minimalne" jest niczym innym jak sformułowaniem wartości kultowej dzieła sztuki w kategoriach przestrzenno-czasowego postrzegania. Oddalenie jest przeciwieństwem bliskości. Rzeczy istotnie odległe nie dadzą się przybliżyć. „Niezbliżalność” [Unnahbarkeit] jest rzeczywiście główną jakością obrazu kultowego. Zgodnie ze swoją naturą pozostaje on w wiecznym „oddaleniu, choćby miało ono być najmniejsze”. Jego materialne zbliżenie w niczym nie umniejsza owego naturalnego dystansu. ${ }^{13}$

Po pierwsze, kult wydaje się tutaj nie tyle przysługiwać określonemu typowi przedmiotów (dzieła sztuki otaczane podziwem i zawierające w sobie odległość czasową oraz walor wyjątkowości), ile pewnemu typowi postrzegania. Sam jest, podobnie jak aura, splotem czasu i przestrzeni generującym wrażenie oddalenia. Po drugie, owa niepowtarzalność aury wcale nie musi znikać pod wpływem rozwoju technik reprodukcji, skoro nawet w ramach tego, co bliskie (albo raczej przybliżone dzięki mediom technicznym), niektóre obrazy wydają się zachowywać margines „niezbliżalności”.

W. Benjamin Dzieło sztuki w dobie reprodukcji technicznej, przeł. J. Sikorski, w: tegoż Anioł historii, s. 210.

13 Tamże. 
Napięcie między fotograficzną i filmową reprodukcją dzieł sztuki a ich aurą nie ma więc u Benjamina charakteru prostej opozycji. Jest raczej punktem zapalnym dialektyki, w ramach której wykuwa się kształt możliwej nowoczesnej formy auratyczności. Dialektyka ta dochodzi do głosu nawet w tych fragmentach jego esejów, w których wydaje się on najbardziej ulegać cokolwiek nostalgicznemu i uproszczonemu estetyzmowi, czyniąc z aury ostatnie echo nieuchronnie znikającego świata autentycznych doświadczeń nie podlegających reprodukcji. „W fotografii wartość ekspozycyjna zaczyna na całej linii wypierać wartość kultową, która jednakże nie zamierza się poddać bez walki, wycofuje się na ostatnie szańce, jakie stanowi dla niej ludzkie oblicze. Portret bynajmniej nieprzypadkowo znajdował się w centralnym punkcie dawnej fotografii. W kulcie pamięci o odległej i wygasłej miłości wartość kultowa obrazu znalazła miejsce swej ostatniej ucieczki. W uchwyconym na gorąco wyrazie ludzkiej twarzy z dawnych fotografii po raz ostatni tchnie aura. I to ona składa się na ich przepojone melancholią, nie dające się z niczym porównać piękno"14 . Jak rozumieć ową resztkę aury szukającej schronienia w starych fotografiach? Czymże byłaby ich aura bez fotografii? Jak można by w ogóle doświadczyć melancholii za utraconą osobą bądź jej aurą właśnie bez momentu zbliżenia, jaki oferuje fotografia. To właśnie dzięki rejestracji ludzkiej twarzy na zdjęciu możemy dostrzec jej niepowtarzalność, która w samym obrazie się nie wyczerpuje, ale dzięki niemu jaśnieje gdzieś w oddali, ku której kieruje nas melancholia.

Podobne dialektyczne napięcie można odnaleźć w drugiej definicji aury, w której Benjamin uznaje ją za zdolność odwzajemniania spojrzenia przez przedmioty lub obrazy i wiąże ze zjawiskiem mimowolnej pamięci. W eseju O kilku motywach u Baudelaire'a czytamy:

Jeśli cechy wyróżniającej obrazy, które wynurzają się z mémoire involontaire, będziemy upatrywać w tym, że obrazy te obdarzone są aurą, to fotografia ma decydujący udział w zjawisku „zaniku aury”. Tym, co w dagerotypii musiało wydawać się nieludzkie - można by rzec zabójcze - było owo (nieustanne zresztą) wpatrywanie się w aparat, który wszak pozyskuje obraz człowieka, nie odwzajemnia mu jednak spojrzenia. A przecież spojrzeniu towarzyszy oczekiwanie, że to, na co patrzymy, spojrzenie nam odwzajemni. Gdy oczekiwanie to zostaje spełnione (a może się ono wiązać nie tylko ze spojrzeniem w zwykłym sensie, lecz także - w myśleniu

Tamże, s. 214-215. 
- $\mathrm{z}$ intencjonalnym spojrzeniem uwagi), wówczas spojrzenie zaznaje w pełni doświadczenia aury. ${ }^{15}$

Można by jednak stwierdzić - przyjmując perspektywę widmontologii, nie tak odległą od refleksji Benjamina, jak mogłoby się wydawać - że w nieodwzajemnionym przez aparat spojrzeniu pozującej do zdjęcia postaci drzemie tyle samo siły podtrzymującej, a nawet wywołującej aurę, co siły skazującej ją na zniknięcie. Uporczywe spojrzenie kogoś znajdującego się na zdjęciu jest bowiem spojrzeniem widmowym, domagającym się wzajemności, której nie sposób mu zaoferować. Znów blokada spojrzenia przez nadmierną bliskość fotograficznej reprodukcji okazuje się w ostatecznej instancji wytwarzać oddalenie. Nic też nie stoi na przeszkodzie, aby porównać przywołujące nas (przypadkowo, bo wpadła nam w ręce jakaś fotografia) spojrzenie uwiecznionej na zdjęciu postaci z tym, jak obrazy w nagłych i mimowolnych nawrotach wspomnień przywołują nas do naszej przeszłości.

Doświadczenie aury opiera się zatem na przeniesieniu reakcji typowej dla dziedziny społecznej na stosunek tego, co nieożywione, lub natury do człowieka. Ten, kto jest oglądany lub sądzi, że jest oglądany, rzuca spojrzenie. Doświadczyć aury pewnego zjawiska to użyczyć mu zdolności do rzucania spojrzeń. Odpowiadają temu znaleziska mémoire involontaire. ${ }^{16}$

Gdy pojawia się w naszej pamięci nagle i niezależnie od (albo wbrew) świadomej woli pewne spojrzenie, wydaje się jakby stawało się ono żywsze i bardziej aktywne niż my sami. W tym sensie można powiedzieć, że jesteśmy przez nie oglądani, bardziej niż sami jesteśmy w stanie ogarnąć je naszym spojrzeniem. Oplata nas ono niczym aureola, zanurzając zarazem w intensywnym świetle nagłego powrotu oraz budując dystans charakterystyczny dla tego, co już minione. W tym miejscu obie definicje aury u Benjamina wydają się ze sobą spotykać, ponieważ odwzajemnienie spojrzenia przez przedmioty czy obrazy można rozumieć jako pewien stosunek między bliskością i dalą, pewien wymiar ich dialektyki. Ujawnia się to tym silniej, im bardziej Benjamin stara się pojęcie aury ograniczyć i dookreślić. W Pasażach zestawia je z kategorią śladu, pisząc:

15 W. Benjamin O kilku motywach u Baudelaire'a (1939), przeł. A. Lipszyc, w: tegoż Konstelacje. Wybór tekstów, Wydawnictwo UJ, Kraków 2013, S. 303.

16 Tamże, s. 303-304. 
Ślad a aura. Ślad jest objawieniem bliskości, tym, co ona po sobie zostawia, jakkolwiek byłaby teraz daleko. Aura to objawienie oddali, jakkolwiek blisko byłoby to, co ją spowodowało. Poprzez ślad zawładamy rzeczą, poprzez aurę to ona nami zawłada. ${ }^{17}$

Ale czy charakterystyczne dla owych zjawisk nie jest właśnie to, że żadna $\mathrm{z}$ dwóch wspomnianych tu form władzy nie jest absolutna i że natychmiast wywołuje swoje przeciwieństwo. Aby ślad był śladem, nie może dawać nam dostępu do samej rzeczy, lecz musi - przybliżając nam ją - zaznaczyć zarazem jej umykanie. Podobnie jest z aurą: włada nami jedynie o tyle, o ile zjawia się przed naszymi oczami dzięki śladom, jako ich naddatek, zarazem wewnątrz i na zewnątrz przedstawienia, które przybliża nam rzeczy.

W pismach Benjamina można odnaleźć jeszcze jedną definicję aury, wyłaniającą się z jego narkotycznych eksperymentów. Tym razem nie jest ona związana z rozważaniami nad nowymi mediami technicznej reprodukcji, lecz nad medium samego haszyszu oraz modyfikacjami wprowadzanymi przezeń do ludzkiej percepcji.

Pod trzema względami przeciwstawiłem - bynajmniej nie schematycznie - prawdziwą aurę konwencjonalnym, banalnym wyobrażeniom teozofów. Po pierwsze, prawdziwa aura towarzyszy wszystkim rzeczom. Nie tylko niektórym, jak ludzie mniemają. Po drugie, zmienia się zupełnie, w sposób zasadniczy z każdym ruchem, jaki wykonuje przynależna jej rzecz. Po trzecie, prawdziwej aury nie można przedstawiać sobie jako nieskazitelnych, spirytualistycznych, magicznych promieni, tak jak się to robi w prymitywnych książkach mistycznych. Wyróżnikiem prawdziwej aury jest raczej ornament, obrzeże ornamentowe, $w$ którym rzecz lub istota tkwi pewnie niczym w futerale. ${ }^{18}$

Aura nie jest zjawiskiem zarezerwowanym dla określonego typu przedmiotów, lecz wyłania się z czasowo-przestrzennych sieci percepcji, stanowi jej specyficzną fałdę. Zobaczyć jej powszechność można natomiast dzięki doświadczeniu rauszu, do którego dostęp dają narkotyki. One także wskazują na ruchliwość rzeczywistości, odsłaniają pod powierzchnią zastygłych wyglądów i opisujących je kategorii, intensywny ruch zjawisk. Aura nie jest

W. Benjamin Pasaże, przeł. I. Kania, Wydawnictwo Literackie, Kraków 2005, s. 493.

18 W. Benjamin O haszyszu, przeł. E. Drzazgowska, Aletheia, Warszawa 2010, s. 161. 
więc statyczną kategorią przysługującą rzeczom, ich własnością, lecz pewnym wymiarem ich ruchu, można nawet powiedzieć - owego ruchu powabem. Rausz narkotykowy pozwala nam dostrzec podwójny ruch - rzeczy i ich aury - zbliżając nas tym samym do czegoś, co Henri Bergson uznał, w swym eseju poświęconym myśli Felixa Ravaissona, za istotę wizji artystycznej. Poszukuje ona „ruchu, którego oko nie widzi, czegoś poza samym ruchem, co jest jeszcze bardziej tajemnicze, źródłowej intencji, fundamentalnej aspiracji osoby, prostej myśli równoważącej nieskończone bogactwo form i kolorów"19.

Czymś wewnętrznym, zarazem przynależnym i nieprzynależnym ruchowi przedmiotów jest również ornament, który Benjamin uznaje za trzecią kategorię opisującą doświadczenie aury w trakcie narkotykowego rauszu.

Nie ma bardziej niezbitego uzasadnienia crocku niż świadomość momentalnego wniknięcia z jego pomocą w ów tajemniczy, w ogólności najbardziej niedostępny świat powierzchni, który tworzy ornament. Jak wiadomo, spotykamy go prawie wszędzie. Mimo to niewiele jest rzeczy, wobec których nasz dar ujmowania tak zawodzi, jak wobec niego. Zazwyczaj niemal go właściwie nie dostrzegamy. ${ }^{20}$

Ornament jest więc tajemniczy i na co dzień niedostępny nie dlatego, że kryje się gdzieś w przepastnych głębinach rzeczywistości, lecz przeciwnie, z uwagi na swoją powszechną dostępność, nieustanne trwanie na powierzchni rzeczy. Najbardziej skryte jest więc to, co zarazem pozostaje najbardziej wyeksponowane. Co więcej, ten fragment rozważań Benjamina zdaje się sugerować, że to w ornamencie znajduje się właściwa dla aury dal, niezbliżalność samego „świata powierzchni” pogrążonego w nieustannym ruchu.

Czy techniczna reprodukcja nie dotyka w pierwszej kolejności właśnie powierzchni rzeczy, pomnażając masowo ich zewnętrzne wyglądy? W Dziele sztuki w dobie reprodukcji technicznej to film stanowi według Benjamina medium najpotężniej kwestionujące dawną aurę przedmiotów, prowadząc tym samym do gwałtownego „wstrząsu tradycji [Erschütterung der Tradition] stanowiącego odwrotną stronę współczesnego kryzysu i odnowy ludzkości"21. Użyte tutaj niemieckie słowo Kehrseite może oznaczać zarówno wadę, negatywną

\footnotetext{
19 H. Bergson La vie et l'œuvre de Ravaisson (1904), w: tegoż La pensée et le mouvant, P.U.F., Paris 1955 , s. 265 . 
stronę pewnego zjawiska, jak i jej stronę odwrotną, niczym rewers monety. Wstrząs tradycji wywołany przez kino może więc być zarówno rzeczywistą i fundamentalną katastrofą zawartą w powtarzalnych cyklach kryzysu i odnowy, w rytm których toczą się dzieje kultury, albo przeciwnie, rewersem tych załamań, czymś, co wprawia tradycję we właściwy jej ruch, czyniąc ją tym samym „czymś jak najbardziej żywym, czymś niezwykle podatnym na przeobrażenia"22. Ostatecznie więc z eseju Benjamina można wyczytać dwie całkiem rozbieżne - by nie powiedzieć sprzeczne - wizje kulturowych przemian i roli, jaką odgrywa w nich medium kina. Z jednej strony jest ono powielaczem powierzchni, który niszczy ich aurę, zastępując ją wysiloną bliskością masowej technicznej reprodukcji. Co więcej, wydaje się, że w tym procesie multiplikacji paradoksalnie wytraca się gdzieś po drodze auratyczny ruch przypisany każdej rzeczy i w każdej z nich wytwarzający drobny margines ornamentu. Z drugiej jednak strony można powiedzieć, że kino - radykalizując proces zaniku aury rozpoczęty przez fotografię - dokonuje wstrząsu tradycji, ożywiając ją i tworząc warunki dla pojawienia się nowej auratyczności, która nie będzie już zagrożona przez techniczną reprodukcję i zamiast szukać schronienia w kultowych wymiarach percepcji, otworzy się w pełni na dynamikę nowoczesności. W ten sposób, powielając powierzchnie rzeczy, kino aktywizowałoby także ornament zawarty w powszechnym ruchu przedmiotów, wydobywałoby jego wewnętrzny powab.

\section{Fotogenia, aura ruchu}

Jak zauważa Miriam Bratu Hansen, wielowątkowe rozważania Benjamina na temat pojęcia aury skłaniają do wniosku, że „relacja między aurą a techniczną reprodukcją, podobnie jak między aurą a masami, nie musi sprowadzać się do binarnej opozycji wykluczających się terminów" ${ }^{23}$. Co więcej, być może dałoby się wysnuć stąd również myśl, że media oparte na technicznej reprodukcji i masowym zasięgu wytwarzają nową, specyficzną dla siebie formę aury. Skoro kluczowym a zarazem najbardziej dwuznacznym elementem tej układanki jest u Benjamina kino, czy można by - w ramach myślowego eksperymentu prowadzącego występujące w jego refleksji napięcia do skrajności - przedstawić wszystkie składniki jego definicji aury jako elementy pewnej wizji samego kina? Wówczas być może ujawniłoby ono swoją głęboką

22 Tamże, s. 209.

23 M. Bratu Hansen Benjamin's Aura, s. 375. 
kulturową moc, znacznie wykraczającą poza obiegowe interpretacje czyniące $\mathrm{z}$ niego jedynie kolejne medium technicznej reprodukcji.

Po pierwsze więc, doświadczenie kina, mimo jego zdolności do oswajania nas z przedmiotami i czynienia ich coraz bliższymi, zawierałoby w sobie zasadniczą niezbliżalność, rodzaj dali, do której odsyłałyby nawet przedmioty których widok na dużym ekranie wydaje się nas całkowicie pochłaniać i nad nami dominować. Niezbliżalność byłaby zarazem niedostępnością tego, co najbliższe, co niemal całkowicie splata się z naszymi fantazjami i emocjami. Oglądanie filmów w ciemnej sali projekcyjnej jest więc niewątpliwie - po drugie - okazją do spotkania z czymś, co patrzy na nas. Każdy obraz jawi się naszym oczom jako coś zarazem bliskiego i odległego, swojskiego i obcego, sprawiając tym samym, że zostajemy niejako przyłapani na swoich fantazjach, spotykamy się z nimi niczym z nawiedzającą nas zjawą. Tak jakby ekran był przestrzenią jednoczesnej projekcji i introjekcji, tworząc figury zarazem zbyt bliskie, zbyt intymnie splecione z naszymi psychicznymi widmami i zbyt odległe, by po prostu uznać je za swoje. To niewątpliwie spotkanie $\mathrm{z}$ widmem, w którym gubimy się nie mniej niż bohaterowie pierwszych scen Hamleta. Kino, po trzecie, jest według Benjamina medium nowoczesnego rauszu wciągającego widzów w pęd obrazów jaśniejących na ekranie. Dzięki temu upowszechnia aurę, nie przypisuje jej wyłącznie wybranym przedmiotom - np. dziełom sztuki - lecz ujawnia jej obecność w całej rzeczywistości. Po czwarte, kino ujawnia auratyczność ruchu, celebruje go nie tylko ze względu na to, że jest ruchomą fotografią, ale także dlatego, że wszystkie specyficzne dla niego środki wyrazu dotyczą z konieczności sposobów jego organizowania. Po piąte wreszcie, kino wypełnia ruch aurą właśnie dlatego, że ujmuje wszelkie jego ornamenty, jest grą powierzchni, które nieustannie nachodzą na siebie, mnożą się i dynamicznie rozwijają.

Spojrzenie na kino jako na miejsce kształtowania się w pełni nowoczesnej i, co więcej, opartej na reprodukcji formy doświadczenia auratycznego zbliża myśl Benjamina do dyskusji na temat fotogenii, prowadzonych intensywnie przez awangardowych francuskich filmowców i krytyków w latach 20. ubiegłego wieku, a więc tuż przed tym, jak autor Małej historii fotografii zajął się problemem aury. Pojęcie fotogenii, po raz pierwszy użyte przez Louisa Dellu$\mathrm{ca}^{24}$, miało określać to, co specyficzne dla filmowej prezentacji rzeczywistości,

24 Por. L. Delluc Photogénie, Brunoff, Paris 1920 (fragmenty w przekładzie polskim: L. Delluc Fotogenia (fragmenty), przeł. T. Lubelski, w: Europejskie manifesty kina. Antologia, red. A. Gwóźdź, Wiedza Powszechna, Warszawa 2002, s. 46-53. 
nazywać unikalną wartość, jaką do ludzkiego doświadczenia wprowadziło kino. Zarazem jednak trudno było dokładnie określić, czym jest fotogenia i dzięki jakim procedurom można ją rozpoznać lub zdefiniować. Z uwagi na jednoczesną popularność i mglistość tej kategorii, Karol Irzykowski pisał w Dziesiątej muzie, że „tą dziwną nazwą objęto wszystko, co daje piękny obraz w projekcji, czyli całość własności, które się przyczyniają do świetności żywego obrazu i sprawiają, że nie chybia wrażenia"25.

W czym należy szukać owej wyjątkowej cechy, o której obecności tak wiele pisano i zarazem, według Irzykowskiego, stosunkowo niewiele powiedziano? Kategoria ta nazywa przede wszystkim „kinetyczne walory filmu”, czyli sposób, w jaki kino jest w stanie zagospodarować swoją główną domenę"26. Skoro tak, być może sama nazwa powinna zostać zmieniona, aby lepiej nazwać oczywistość swojego zastosowania.

Wywnioskowałem tylko tyle, że „fotogeniczny” znaczy tyle, co „ściśle kinowy”, „odpowiadający istocie kina”. Lecz w takim razie, skoro to jest tylko tautologia, czyż nie uczciwiej używać po prostu słowa „kinowy”, „kinetyczny”, ,kinegraficzny” albo, aby zachować podźwięk, niech będzie „kinogeniczny”? Przecież „fotogenia” znaczy dosłownie: narodziny światła, lub: narodziny w świetle; więc o ileż odpowiedniejsze byłoby słowo znaczące tyle co: ruchorodny? ${ }^{27}$

Kino ukazuje zatem ruchliwość rzeczy dzięki światłu, spowija je specyficzną aurą, która komunikuje w obrazie coś, co można by nazwać wewnętrznym światłem samego ruchu, jego promienistym ornamentem. To dlatego, niezależnie od swego sceptycyzmu, Irzykowski mógł jednak uznać fotogenię za „wyraz skupiający w sobie różne pytajniki kina”, pozwalający jemu samemu odkryć, że „pojęcie kina nie pokrywa się całkowicie z pojęciem ruchu”28, co można dopowiedzieć już za niego - oznacza przede wszystkim, że w ramach kina sam ruch staje się czymś więcej niż był przedtem. I dzieje się tak właśnie dzięki fotogenii albo, mówiąc inaczej, ta przemiana nazywa się fotogenią.

\footnotetext{
25 K. Irzykowski Dziesiąta muza oraz Pomniejsze pisma filmowe, s. 139.

26 Tamże, s. 141.

27 Tamże, s. 143.

28 Tamże, s. 155 .
} 
Nigdzie jednak refleksja nad fotogenią jako przemianą wizji świata, wprowadzoną do nowoczesnej kultury za sprawą wynalazku kina, nie osiągnęła tak rozbudowanego wyrazu, jak w pismach i eksperymentach filmowych Jeana Epsteina. Francuski twórca awangardowy, autor tak sztandarowych dla rozwoju języka filmowego dzieł jak Upadek domu Usherów (1928) czy Le tempestaire (1947), powracał w swych pismach wielokrotnie do kategorii stworzonej przez Delluca, próbując zarazem uczynić z niej narzędzie możliwie rozbudowanej definicji samego kina.

Co to jest fotogenia? Nazwałbym fotogenicznym wszelki aspekt rzeczy, bytów i dusz, który wzmaga swoją wartość moralną poprzez filmową reprodukcję. Zaś wszelki aspekt, który nie potęguje się w ten sposób nie jest fotogeniczny, nie jest częścią sztuki filmowej. ${ }^{29}$

Można więc powiedzieć - odnosząc się po części do słownika Benjaminowskich rozważań nad aurą - że kino czyni rzeczy większymi niż w rzeczywistości, choć zarazem dokonuje tego przez zbliżenie, które Epstein uznawał skądinąd za "duszę kina" ${ }^{30}$. W tym akcie przybliżania rzeczy nie ma jednak nic z prostego oswojenia ani z ograniczania ich do prostych podobizn. To właśnie dzięki zbliżeniu możemy w pełni zobaczyć majestat ich wewnętrznych ruchów, które nasycają obraz. Dlatego też Esptein, rozwijając swoją definicję fotogenii, stwierdzi też, że „jedynie ruchome aspekty świata, rzeczy i dusz, mogą zwiększyć swoją wartość moralną pod wpływem filmowej reprodukcji”¹.

Skoro jednak ruch w ramach medium filmowego dzieli się i mnoży wewnętrznie, dopuszczając do głosu wszystkie swoje ornamenty, to fotogenia również nie może ograniczać się do ruchomych aspektów rzeczy rozumianych w sposób czysto mechanistyczny. Epstein dostrzega w niej trzy dodatkowe wymiary: życie, osobowość i czas.

Kino obdarza najbardziej zamrożone wyglądy rzeczy i byty największym dobrem poprzedzającym śmierć: życiem. I życie to oddaje im poprzez jego najbardziej doniosły aspekt: osobowość. Osobowość przekazuje inteligencję. Osobowość jest widzialną duszą rzeczy i ludzi, ich jawnym

29 J. Epstein Le cinématographe vu de l'Etna (1926), w: tegoż Écrits sur le cinéma, t. 1: 1921-1947, Seghers, Paris 1974, s. 137.

J. Epstein Grossissement, w: tegoż Écrits sur le cinéma, t. 1: 1921-1947, s. 93.

31 J. Epstein Le cinématographe vu de l'Etna (1926), s. 138. 
dziedzictwem, ich niezapomnianą przeszłością i przyszłością obecną już teraz. ${ }^{32}$

W tych słowach trzy aspekty fotogenii łączą się ze sobą w nierozerwalną całość. Ruch staje się życiem dzięki temu, że wypełnia sobą formę obrazu, przekazuje zawarty w ruchu powab. On zaś odkrywa inteligencję i osobowość we wszystkich rzeczach, wypełniając je osobliwą aurą ruchu oraz zmieniając ich percepcję w coś na kształt spotkania z duchem. Wreszcie, wszystko to możliwe jest dzięki temu, że w obrazie filmowym ruch jest nierozerwalnie związany z czasem, który - jak pisał Jean Louis Schefer - „po raz pierwszy przeniknął

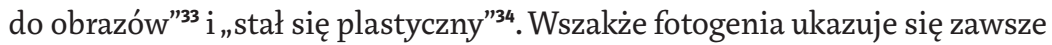
jedynie w interwale, w krótkim błysku wewnętrznego światła ruchu - ,jest wartością z poziomu sekundy"35, jak zauważa Epstein.

Tylko taki czas jest nam dany na spotkanie $\mathrm{z}$ widmem tkwiącym w nas samych. Dłuższe kontakty mogą nawet okazać się groźne, jak dowodzi historia księcia Danii. Jacques Derrida w jednym z wywiadów stwierdził, że

doświadczenie kinematograficzne należy, na wskroś, do widmowości. [...] Widmo, ani żywe ani martwe, znajduje się w samym centrum niektórych moich pism, dzięki temu, przynajmniej dla mnie, możliwe wydaje się mi się jakiekolwiek myślenie na temat kina. ${ }^{36}$

Wszystko w tej wypowiedzi wydaje się jasne, być może nawet - w swej ogólności - aż nazbyt oczywiste. Jedyna osobliwie brzmiąca fraza to owo „należenie do widmowości", które - oprócz zrozumiałego zrównania doświadczenia filmowego z doświadczeniem obcowania z duchami - mówi też, że to dziwne spotkanie nie należy do nikogo. Podobnie jak ów krótki błysk aury, w którym rzeczy, ludzie i dusze, o jakich rozprawiali Benjamin z Epsteinem, wydają się

32

33 J. L. Schefer Du monde et du mouvement des images, Éditions de l'Étoile/Cahiers du Cinéma, Paris 1997, s. 17.

34 Tamże, s. 18.

35 J. Epstein Grossissement, s. 93.

36 J. Derrida Le cinéma et ses fantômes. Entretien avec Antoine de Baecque et Thierry Jousse, w: tegoż Penser à ne pas voir. Écrit sur les arts du visible (1979-2004), Éditions de la Différence, Paris 2013, s. 319. 
wciąż świecić, błyszczeć i jaśnieć jakimś odległym światłem, tak jakby nie byli do końca z tego świata.

\section{Abstract}

\section{Paweł Mościcki}

THE INSTITUTE OF LITERARY RESEARCH OF THE POLISH ACADEMY OF SCIENCES (WARSAW)

The Rebirth of the Aura out of the Spirit of Photogénie

How useful is the concept of the aura in film studies, given the debates on the spectral character of the filmic medium? This article comprises two parts. The first analyses the different meanings of aura in Walter Benjamin's works, especially its ambiguity in relation to the invention of film. The second part examines the relationship between aura and photogénie as theorised by Jean Epstein.

\section{Keywords}

film, aura, photogénie, technical reproduction, spectre, Walter Benjamin, Jean Epstein 